\section{Vasilije \\ Gvozdenović $^{1}$}

Odeljenje za

psihologiju, Filozofski

fakultet, Univerzitet u

Beogradu

\section{Kaja Damnjanović}

\section{Laboratorija za}

eksperimentalnu

psihologiju, Odeljenje

za psihologiju,

Filozofski fakultet, Univerzitet u Beogradu

\section{Adresa autora: \\ vgvozden@f.bg.ac.rs.}

Primljeno: 27. 05. 2015.

Primljena korekcija:

02. 09. 2015.

Prihvaćeno za štampu:

01. 10. 2015.

\section{UTICAJ NIVOA VEROVATNOĆE NA EFEKAT OKVIRA PRI REFERENTNOJ TAČKI GUBITKA $^{2}$}

U istraživanjima dejstva okvira rizičnog izbora se uglavnom primenjuju zadaci u kojima je eksperimentalna referentna tačka (ERT) smeštena u zonu dobitka (situacija nagradne igre). Cilj izvedenog istraživanja je bio ispitivanje obrasca efekta okvira u funkciji nivoa verovatnoće prikazanog u zadatku, pri čemu je ERT smeštena u zonu gubitka (situacija naplate računa). Potvrđena je generalna averzija prema riziku u monetarnom domenu, registrovana u ranijim istraživanjima. Rezultati pokazuju da jezička manipulacija koja predstavlja okvir utiče na izbor kada je mogućnost potpunog gubtika (iskazana verovatnoćom) procenjena kao dovoljno niska. Tumačenje dobijenih nalaza u svetlu ranijih istraživanja upućuje na zaključak da nivo verovatnoće i eksperimentalna referentna tačka u interakciji deluju na efekat okvira. Kada je pred ispitanikom prinudni izbor između sigurnog dobitka i rizičnog dobitka (ERT u zoni dobitka), okvir deluje na najvišim nivoima verovatnoće, i obrnuto, kada je ERT u zoni gubitka, okvir ostvaruje efekat na najnižim nivoima verovatnoće. Rezultati su u skladu sa dosadašnjim nalazima koji upućuju na zaključak da averzija prema riziku nije jednoznačna i da zavisi od toga da li donosilac odluke trošak opaža kao smanjenje prihoda ili kao gubitak, kao i od količine „spašenog” novca. lako sklonost ka riziku u negativnom okviru i različita ponašanja u zonama dobitka i gubitka jesu u skladu sa kumulativnom teorijom izgleda, različiti obrasci odlučivanja u zavisnosti od ERT nisu u potpunosti objašnjivi ovim modelom.

Ključne reči: efekat okvira, rizično odlučivanje, verovatnoća ishoda, referentna tačka, gubitak

\footnotetext{
${ }^{2}$ Ovaj rad potpomognut je sredstvima Ministarstva prosvete, nauke i tehnološkog razvoja, projekat br. ON 179033.
} 
Efekat okvira postoji kada različiti opisi formalno identičnih ishoda odluka dovode do različitih izbora - sa promenom okvira menja se i redosled preferencija donosioca odluke (Tversky \& Kahneman, 1981). To da li ćemo donosiocu odluke (DO) ishode opcija opisati naglašavajući pozitivne aspekte („polupuna čaša”) ili negativne aspekte („poluprazna čaša”) može da utiče ne samo na konačnu odluku, već i na odnos DO prema riziku. Odlučivanje u uslovima rizika odnosi se na probleme odlučivanja u kojima ispitanik ima zadatak da izabere između dve ponuđene opcije istih (očekivanih) vrednosti, koje se razlikuju po rizičnosti: jedna opcija je nerizična (sigurna), a druga je rizična. Svaku od opcija možemo da uokvirimo: kada u opisu situacije naglašavamo povoljne aspekte ishoda, koristimo pozitivan okvir (npr. preživi 90\% ljudi), a kada naglašavamo nepovoljne aspekte istih ishoda (umire 10\% ljudi) koristimo negativan okvir. Ovakve jezičke manipulacije u opisima mogućih ishoda nazivamo okvirom, a empirijski fenomen promene redosleda preferencija sigurne i rizične opcije, a koji je posledica tih različitih opisa efektom okvira. Važno je da istaknemo da u zadatku rizičnog odlučivanja ne postoji jedan normativno tačan izbor. Drugim rečima, za teoriju odlučivanja nije relevantno da li DO preferira sigurnu ili rizičnu opciju istih očekivanih vrednosti, već je od značaja da ostane dosledan sopstvenom izboru bez obzira na to kako smo mu predstavili opcije.

Rizična opcija sadrži informaciju o neto-vrednosti i o verovatnoćama povoljnog i nepovoljnog ishoda. U ovakvim zadacima okvir se smešta na obe opcije, pa tako u tipičnom eksperimentu postoje četiri različite mogućnosti: po dve pozitivne i dve negativne, sigurne i rizične opcije. Ovde spada problem azijske bolesti, a zatim varijacije i srodni zadaci korišćeni u nizu istraživanja (npr. Frisch, 1993; Jou, Shanteau, \& Harris, 1996; Kühberger, 1995; Reyna \& Brainerd, 1991; Takemura, 1994; Tversky \& Kahneman, 1981). Većina istraživanja bila je usmerena na merenje promene u sklonosti riziku preko poređenja izbora rizičnih opcija.

Eksperimentacija okvirom je variranje opisa formalno identičnih problema sa ciljem naglašavanja različitih aspekata predočene situacije: dobitaka i gubitaka. Na talasu velikog uspeha koji su postigli Tversky i Kahneman, rezultati prvih, često replikativnih istraživanja potvrđivali su robusnost efekta okvira (za pregled ranih istraživanja videti Kühberger, 1998; Levin, Schneider, \& Gaeth, 1998). Promena u proceduri ispitivanja, usložnjavanje i odstupanje zadataka od klasičnog problema azijske bolesti promenili su tu sliku, te se u poslednjoj deceniji prošlog veka beleži veliki broj istraživanja koja izveštavaju o nepostojanju efekta okvira (Ganzach \& Schul, 1995; Li \& Adams, 1995; Schneider, 1992; Shafir, 1993; Sniezek, Pease, \& Switzer, 1990; Urbany \& Dickson, 1990; Wang, 1996a; Wedell, 1997).

\section{Struktura zadatka}

Zadaci u navedenim studijama su se razlikovali po tipu okvira, po referentnim tačkama, po korišćenim merama (od rangovanja do izbora), kao i po tome da li su mere bili grupne ili individualne, a opšti nalaz je da efekat okvira slabi 
kako zadatak više odstupa od formata problema azijske bolesti, bez preciziranja koji su parametri odgovorni za takve promene (Kühberger, 1998). Zadaci odlučivanja u uslovima rizika imaju površinsku (meku) i dubinsku (tvrdu) strukturu. Dubinskom strukturom označavamo formalne osobenosti zadatka rizičnog odlučivanja, tj. nužne i dovoljne elemente i način na koji je konstruisan zadatak. Zadaci uobičajeno imaju ove elemente: prolog, sigurnu i rizičnu opciju koja ima sintaksu lutrije. Površinska struktura se odnosi na sadržaj o kom se odlučuje i na sve ostale varijacije u zadacima koje ne menjaju formu zadatka. Da li raspolažemo svojim ili tuđim novcem u zadatku zamišljenog izbora, variranje verovatnoće ishoda i slični aspekti predstavljaju primere parametara površinske strukture zadatka.

Posebni aspekt površinske strukture zadatka je domen o kom se odlučuje. Efekti okvira ispitivani su u različitim domenima (kontekstima), tj. zadaci korišćeni u eksperimentima odnosili su se na različite domene ljudskog života: zdravlje, novac, preživljavanje/umiranje, vlasništvo, vreme kao resurs, kupovinu, moral i kockanje (Kühberger, 1998). Nalazi sugerišu da efekat okvira jeste u vezi sa „jedinicom mere" dobitka/gubitka. Razlika između efekata okvira u različitim domenima tema je brojnih istraživanja (videti npr. Fagley \& Miller, 1997; Haward, Murphy, \& Lorenz, 2008; Huang \& Wang, 2010; Wang, 1996b). U različitim domenima odlučivanja, različiti aspekti odlučivanja su od posebnog značaja. Na primer, u nekim oblastima odlučivanja, kao što su osiguranje i novčano investiranje, precizno određenje tačke u kojoj se prelazi sa potcenjivanja na precenjivanje verovatnoća je važno, dok je ono manje bitno u nekim drugim oblastima odlučivanja (Huang \& Wang, 2010). Rezultati istraživanja koja su usmerena na odlučivanje o osiguranju i porezima, beleže i uticaj ispitanikovog odnosa prema ulogu kojim raspolaže na averziju prema gubitku i na efekat okvira (npr. Chang, Nichols, \& Schultz, 1987), i to tako što donosilac odluke na trošak može da gleda kao na gubitak ili kao na smanjenje prihoda (ili investiranje), što se potom očitava na pomeranje referentne tačke. Dalje, ispitanici donose rizičnije odluke u vezi sa životima, nego u vezi sa novcem (Damnjanović, 2013; Fagley \& Miller, 1997; Kashima \& Maher, 1995; Schneider, 1992; Tversky \& Kahneman, 1981; Wang, 1996b) i vlasništvom (Jou et al., 1996).

\section{Efekat okvira i teorija izgleda}

Teorija izgleda (engl. Prospect theory; Kahneman \& Tversky, 1979) predstavlja dominantni bihejvioralni model odlučivanja u uslovima rizika. Efekti okvira ukazuju na to da redosled preferencija nije invarijantan u odnosu na proceduru ispitivanja ili na različite opise situacije. Tversky i Kahneman definišu „okvir odluke" da bi opisali koncepcije donosioca odluke u vezi sa delima, ishodima i kontigencijama povezanim sa određenim izborom. „Okvir koji DO usvoji određen je delimično formulacijom problema, a delimično ličnim karakateristikama i pristrasnostima samog donosioca odluke - koje formiraju referentnu tačku iz koje se prilazi problemu" (Tversky \& Kahneman, 1981, str. 455). 
Šta se, dakle, dešava u procesu odlučivanja kada je DO suočen sa prinudnim izborom između sigurne i rizične opcije? Na osnovu konceptualizacije efekta okvira i drugih emprijskih fenomena odstupanja od aksioma normativno racionalnog odlučivanja, Kahneman i Tversky (Kahneman \& Tversky, 1979) postavljaju teoriju izgleda (TI), čiji su ključni koncepti vezani za dve funkcije - funkciju vrednosti i funkciju ponderisanja verovatnoća.

Funkcija vrednosti (Slika 1) odražava odnos DO prema ishodima akcija. Vrednost (engl. value) je definisana u terminima dobitaka i gubitaka, tj. odstupanjem od referentne tačke (engl. reference point). Tversky i Kahneman polaze od toga da pri procenjivanju vrednosti postoji vrednost koja predstavlja normu (pomenuta referentna tačka), u odnosu na koju se ishod vrednuje kao dobitak, odnosno kao gubitak - čime se formira funkcija vrednosti koja je osnova za odlučivanje.



Slika 1. Funkcija vrednosti.

Funkcija vrednosti ima sledeće osobine: referencijalna zavisnost (nosioci vrednosti [y] su dobici i gubici određeni u odnosu na referentnu tačku, tj. početnu poziciju, presek x i y); odbojnost prema gubitku - nagib funkcije je veći u negativnom nego u pozitivnom domenu, tj. gubici se procenjuju većim od ekvivalentno vrednih dobitaka (gubitak od 1000 RSD ima veću težinu od dobitka 1000 RSD); i opadajuća osetljivost - marginalne vrednosti i dobitaka i gubitaka opadaju sa njihovom udaljenošću od referentne tačke, odnosno diferencijalni prag se povećava sa udaljenjem od početne pozicije (Kahneman \& Tversky, 1979).

Teorija izgleda uvodi koncept referentne tačke kao granice između zone dobitaka i zone gubitaka. Dve zone investiranja prvi pretpostavlja Markowitz (1952), ali ne razmatra prelaz iz jedne u drugu zonu. Implikacija razlikovanja ove dve zone je pretpostavka o različitom psihičkom tretmanu dobitaka i gubitaka: sklonosti ka riziku i averzije prema riziku. Teorija izgleda predviđa da se sa promenom okvira u kojem su prikazani mogući ishodi menja i referentna tačka, a budući da su naše 
preferencije (vrednosti) u funkciji referentne tačke, menjaju se i naše preferencije. Ako ishod prikažemo pozitivno, smeštamo ga u zonu dobitka („polupuna čaša”), funkcija je konveksna naviše i DO će nastojati da izbegava rizik, tj. odbiće rizičnu opciju ukoliko mu je ponuđena i sigurna opcija. Nasuport tome, kad koristimo negativni okvir - smeštamo ga u zonu gubitka („poluprazna čaša”), funkcija vrednosti je konveksna naniže i DO će biti sklon riziku (Slika 1). Funkcija vrednosti nije funkcija celokupnog bogatstva donosioca odluke, već funkcija promene bogatstva.

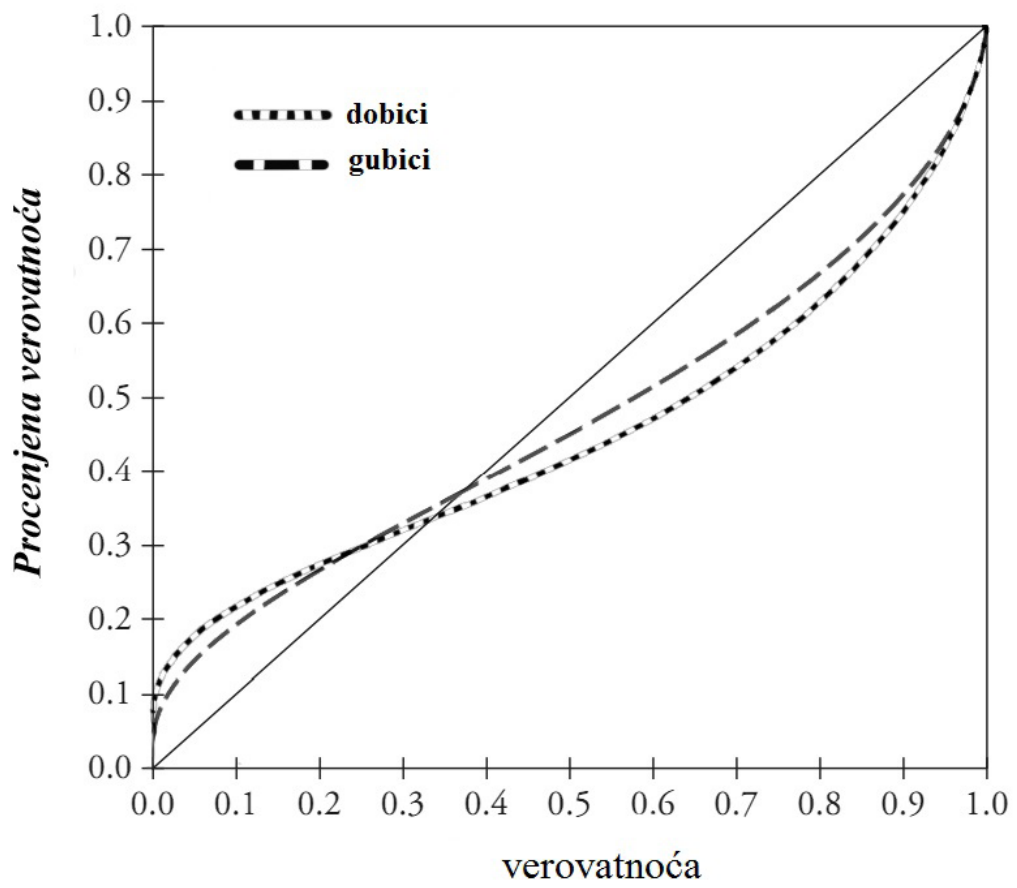

Slika 2. Funkcija težinskih koeficijenata odluke (Tversky \& Kahneman, 1992).

Funkcija ponderisanja verovatnoća (Slika 2) odluke odražava odnos DO prema verovatnoćama događaja. Oblik funkcije otkriva da je naš odnos prema verovatnoćama subjektivan, $\mathrm{tj}$. da se iste razlike u verovatnoćama duž kontinuuma od 0 do 1 ne doživljavaju na isti način. Raniji modeli, pre teorije izgleda (normativni) su pretpostavljali da DO verovatnoću 0.5 za pobedu vrednuje kao: verovatnoću 0.5 za pobedu. Nasuprot tome, teorija izgleda tretira preferencije u funkciji težinskih koeficijenata odluke i pretpostavlja da ovi ponderi ne korespondiraju uvek sa verovatnoćama. Matematički, vrednost verovatnoće je uvek između (uključujući i) 0 i 1 i vrednosti verovatnoće se uvek sabiraju do 1 . Ono što je posebno psihološki intrigantno jeste da ljudi, međutim, drugačije opažaju verovatnoće - kada sude i odlučuju o neizvesnom događaju, čak i kada znaju verovatnoće, donosioci odluka vrednosti tih realnih (datih) verovatnoća ne opažaju kao takve, već koriste pondere verovatnoća (odnosno, potcenjuju ih ili precenjuju). Dakle, postoje objektivne 
verovatnoće i subjektivne, procenjene verovatnoće, koje DO tretira kao objektivne, tj. koje razmatra i na osnovu kojih sudi i odlučuje (maksimizira vrednost na osnovu subjektivnih verovantoća), a odnos subjektivnih i objektivnih verovatnoća nije linearan. Tipična funkcija pondera leži iznad dijagonale za niske verovatnoće i ispod dijagonale za srednje i visoke verovatnoće. Funkciju težinskih koeficijenata odluke Tversky i Kahneman razrađuju u kumulativnoj teoriji izgleda (engl. Cumulative prospect theory; Tversky \& Kahneman, 1992).

Verovatnoće 0 i 1 se opažaju kakve zaista i jesu, kao nemoguće i kao izvesno. Međutim, niske verovatnoće se precenjuju ili zanemaruju. Verovatnoća retkog događaja koji je zasićen u našem umu će biti precenjena; slično, verovatnoća retkog događaja koji nije zasićen u našem umu će biti ignorisana. Pored toga, srednje i visoke verovatnoće su potcenjene (na primer, objektivna verovatnoća 0.9 je subjektivno opažena kao 0.7). Pitanja kritične tačke koja predstavlja granicu između visokih i niskih subjektivnih verovatnoća, kao i oblika ove funkcije su i dalje otvorena. U prvoj verziji teorije izgleda (Kahneman \& Tversky, 1979) kao kritičnu vrednost verovatnoće autori navode 0.1, u kumulativnoj teoriji izgleda (Tversky \& Kahneman, 1992) funkcija težinskih koeficijenata je redefinisana i kao kritična tačka verovatnoće se navodi 0.3 (kao na slici 2), dok Kahneman (2011) navodi da se i verovatnoće 0.2 precenjuju.

\section{Problem i ciljevi istraživanja}

Veličina i smer, a i postojanje efekta okvira, imajući u vidu brojne nalaze i modele, nisu jednoznačni i zavise od većeg broja parametara zadatka odlučivanja u uslovima rizika (Kühberger \& Tanner, 2010; Levin et al., 1998; Wang, 1996a). Okvir ne ostvaruje nužno tako snažno dejstvo kao u klasičnom zadatku azijske bolesti, i što je odstupanje od tog zadatka veće to je efekat slabiji (Kühberger, 1998). Empirijski efekat okvira se u istraživanjima registruje brojnim vrstama zadataka, a i tehnike merenja su različite, pa, iako rezultati izveštavaju o postojanju efekta, takvi rezultati nisu samerljivi. 0 dva elementa strukture zadatka postuliranih teorijom izgleda, a to su referentna tačka i verovatnoća, nema zabeleženog većeg broja istraživanja. Postoje, ipak, nalazi koji se indirektno bave ovom problematikom. Što se tiče verovatnoće, nalazi ukazuju na mogućnost zavisnosti efekta okvira od prikazanog nivoa verovatnoće. Na primer, u istraživanju koje upućuje na ovaj zaključak, međutim, nisu kontrolisani uticaj domena odlučivanja, tj. registrovani efekti okvira su ispitivani u više domena (Milićević, Pavličić i Kostić, 2007). Slično važi i za mogući uticaj referentne tačke, tj. zavisnost efekta okvira od nivoa verovatnoće je ispitivana samo u referentnoj tački dobitka (Damnjanović i Gvozdenović, 2014). U tom i sličnim istraživanjima (Wang, 1996b), zadatak rizičnog odlučivanja se odnosio samo na situaciju nagradne igre i mogućnosti manjeg ili većeg dobitka. Referentna tačka, sa druge strane, predstavlja koncept raznorodnog sadržaja, te se može reći da svako istraživanje u kojem se efekat okvira ispituje u različitim domenima odlučivanja zahvata jedan aspekt sadržaja referentne 
tačke. Na primer, nalazi ispitivanja uticaja referentne tačke na rizično odlučivanje o novcu (ali ne i na efekat okvira), pokazuju da trenutni prihod, imetak i budući prihodi imaju različite referentne tačke (Stajkić \& Gvozdenović, 2014; Thaler \& Johnson, 1990).

U većini zadataka rizičnog odlučivanja o novcu situacija u prologu zadatka opisuje zamišljeno sticanje novca srećnim sticajem okolnosti po donosioca odluke. Polazeći od ova dva teorijska koncepta, ciljevi ovog istraživanja su usmereni na preciznije ispitivanje dejstva okvira kada je početna pozicija (eksperimentalna referentna tačka) u rizičnom odlučivanju situacija gubitka, kao i uticaj nivoa verovatnoće u ovakvoj zamišljenoj situaciji. Promenom opisa zamišljene situacije u kojoj se nalazi DO menjala se i početna pozicija DO. Cilj eksperimenta je bio ispitivanje obrasca rizičnog odlučivanja u funkciji verovatnoće u situaciji kada se bira između sigurnog gubitka i rizičnog gubitka (eksperimentalna referentna tačka: gubitak). Drugi aspekt analize prikupljenih podataka je imao za cilj ispitivanje uticaja promene pozicije referentne tačke na odlučivanje, i to kroz poređenje sa obrascem rizičnog odlučivanja u funkciji verovatnoće kada je izbor između sigurnog i rizičnog dobitka iz našeg ranijeg istraživanja (Damnjanović i Gvozdenović, 2014), i drugih istraživanja u kojima je referentna tačka smeštena u zonu dobitka (Wang, 1996b). Dodatno, u ovom istraživanju, cilj je bio da ponudimo novu meru efekta okvira. Domen odlučivanja u ovom istraživanju je monetarni, a početna pozicija opisana u prologu predstavlja gubitak novca, tj. eksperimentalna referentna tačka (ERT) je smeštena u zonu gubitka.

\section{Metod}

\section{Ispitanici i procedura}

Svaki od ukupno 600 ispitanika (prosečnog uzrasta 22.4 godine; 59\% ženskog pola) je odgovarao samo na jedan zadatak rizičnog izbora. Zadatak ispitanika bio je da samostalno izabere jednu od dve ponuđene opcije obeležavanjem preferirane opcije. Odgovaranju je prethodilo pismeno i usmeno uputstvo. Ispitivanje je sprovedeno u grupama od približno 50 ispitanika tokom 2012. i 2013. godine, u ukupno 11 sesija. Ispitanici su bili studenti Univerziteta u Beogradu (Pravni fakultet, Prirodno-matematički fakultet, Fakultet za specijalnu edukaciju i rehabilitaciju). Studenti psihologije nisu učestvovali u istraživanju.

\section{Stimulusi}

Stimulusi su imali formu zadatka odlučivanja u uslovima merljive neizvesnosti (rizika), sa po dve verzije zadatka na svakom nivou okvira (pozitivni i negativni okvir). U zadacima, koji imaju sintaksu lutrije, ispitanici su prinudno (i zamišljeno) birali između nerizične i rizične opcije, pri čemu je vrednost ishoda nerizične opcije jednaka očekivanoj vrednosti ishoda rizične opcije. Svi zadaci su se sastojali 
od prologa (opisa situacije) i dve ponuđene opcije (S i R). U istraživanjima odlučivanja o novcu u zadatku se prikazuje situacija nagradne igre koja ima dve faze, što je, još od Allaisovog paradoksa (Allais, 1953), uobičajen izbor situacije za ispitivanje rizičnog odlučivanja o novcu (videti npr. problem 11 u Kahneman \& Tversky, 1979). Za potrebe našeg istraživanja, osmišljeni su stimulusi na osnovu navedenih zadataka i planiranih manipulacija: umesto (prinudnog) ulaganja u nagradnu igru, ispitanici su prinuđeni da „ulažu” u plaćanje visokog računa. Stimulusi su prikazani u Prilogu 1. Ukupno je konstruisano 12 stimulusa.

\section{Nacrt}

Nacrt istraživanja je 2 x 6. Prvi faktor, okvir, je imao dva nivoa: pozitivan i negativan opis istih opcija. Drugi faktor, nivo verovatnoće (povoljnog ishoda rizične opcije), je imao 6 nivoa $(0.05,0.25,0.40,0.60,0.75,0.90)$. Ukrštanjem faktora nivo verovatnoće sa dva okvira, formirano je 12 zadataka rizičnog odlučivanja, odnosno 6 eksperimentalnih situacija [verovatnoća (6) x okvir (2)]. Od naročitog je značaja bilo izbeći mogućnost propuštanja detektovanja postojećeg efekta. Drugim rečima, u pripremi istraživanja je posebna pažnja bila posvećena minimizovanju greške tipa II, pa tako rezultati analize snage testa pokazuju da je verovatnoća da se bivarijatnim testom detektuje statistički značajan (na nivou $p<.01$ ) efekat okvira one veličine o kojoj izveštavaju Tversky i Kahneman (1981), na uzroku od 20 ispitanika po eksperimentalnoj grupi, iznosi tek 75.3\%. Kada na svakom nivou učestvuje po 30 ispitanika, snaga testa iznosi 93.4\%. Konačno, povećanjem broja ispitanika na 50 po eksperimentalnoj grupi, snaga testa na istom nivou značajnosti raste na visokih $99.8 \%$.

\section{Rezultati}

\section{Faktori sklonosti ka riziku}

Rezultati prikazani u Tabeli 1 potvrđuju generalnu averziju prema riziku u monetarnom domenu, registrovanu u ranijim istraživanjima. Naime, statistički značajna sklonost ka izboru sigurne opcije (u oba okvira) registrovana je na 9 od ukupno 12 zadataka.

Rezultati binarne logističke regresije pokazuju da je interakcija okvira i nivoa verovatnoće u njihovom dejstvu na izbor rizične opcije statistički značajna (Tabela 2). Dalje analize pokazuju da u pozitivnom okviru verovatnoća nije značajan prediktor izbora rizične opcije $\left(B=-0.25, \chi^{2}(1)=0.30, p=.59\right)$, ali da jeste u negativnom okviru $\left(B=-1.88, \exp (B)=0.16, \chi^{2}(1)=17.60, p<.001\right)$. 
Tabela 1

Grupne razlike u sklonosti ka riziku za pozitivi i negativni okvir problema

\begin{tabular}{|c|c|c|c|c|c|c|c|c|}
\hline \multirow{2}{*}{$\begin{array}{c}\text { Nivo } \\
\text { verovatnoće }\end{array}$} & \multirow{2}{*}{$\begin{array}{l}\text { Uokviravanje } \\
\text { ishoda }\end{array}$} & \multicolumn{3}{|c|}{ Izbor rizične opcije } & \multicolumn{4}{|c|}{ Efekat okvira } \\
\hline & & $\mathrm{P}(\%)$ & $\begin{array}{l}95 \% \\
\text { CI- }\end{array}$ & $\begin{array}{l}95 \% \\
\mathrm{CI}+\end{array}$ & $\chi^{2}$ & $r_{\varphi}$ & $p$ & Zaključak \\
\hline \multirow{2}{*}{$5 \%$} & Dobiti & $28 \%$ & 17.47 & 41.67 & \multirow{2}{*}{9.18} & \multirow{2}{*}{.30} & \multirow{2}{*}{.002} & \multirow{2}{*}{ Dvosmerni } \\
\hline & Izgubiti & $58 \%$ & 44.23 & 70.62 & & & & \\
\hline \multirow{2}{*}{$25 \%$} & Dobiti & $22 \%$ & 12.75 & 35.24 & \multirow{2}{*}{5.47} & \multirow{2}{*}{.23} & \multirow{2}{*}{.019} & \multirow{2}{*}{ Jednosmerni } \\
\hline & Izgubiti & $44 \%$ & 31.16 & 57.69 & & & & \\
\hline \multirow{2}{*}{$40 \%$} & Dobiti & $34 \%$ & 22.44 & 47.85 & \multirow{2}{*}{0.05} & \multirow{2}{*}{-.02} & \multirow{2}{*}{.831} & \multirow{2}{*}{ Neznačajan } \\
\hline & Izgubiti & $32 \%$ & 20.76 & 45.81 & & & & \\
\hline \multirow{2}{*}{$60 \%$} & Dobiti & $30 \%$ & 19.10 & 43.75 & \multirow{2}{*}{0} & \multirow{2}{*}{0} & \multirow{2}{*}{1} & \multirow{2}{*}{ Neznačajan } \\
\hline & Izgubiti & $30 \%$ & 19.10 & 43.75 & & & & \\
\hline \multirow{2}{*}{$75 \%$} & Dobiti & $30 \%$ & 19.10 & 43.75 & \multirow{2}{*}{1.10} & \multirow{2}{*}{.11} & \multirow{2}{*}{.301} & \multirow{2}{*}{ Neznačajan } \\
\hline & Izgubiti & $40 \%$ & 27.61 & 53.82 & & & & \\
\hline \multirow{2}{*}{$90 \%$} & Dobiti & $18 \%$ & 9.77 & 30.80 & \multirow{2}{*}{0.71} & \multirow{2}{*}{-.08} & \multirow{2}{*}{.404} & \multirow{2}{*}{ Neznačajan } \\
\hline & Izgubiti & $12 \%$ & 5.62 & 23.80 & & & & \\
\hline
\end{tabular}

Napomena. Svaka eksperimentalna grupa je imala po 50 ispitanika. $\mathrm{P}=$ procenat; 95\% CI- i 95\% CI+ označavaju donju i gornju granicu intervala poverenja od 95\% koje su procenjene Wilsonovim postupkom (Wilson, 1927); $\chi^{2}=$ hi-kvadrat statistik; $r_{\varphi}=$ fi-koeficijent asocijacije; $p=$ nivo značajnosti.

Načelno, izbor rizične opcije je bio tek nešto češći u negativnom okviru ( $\mathrm{P}=$ $36 \%, 95 \%$ CI [30.37, 41.58]), u odnosu na pozitivni okvir (P = 27\%, 95\% CI [22.29, 32.29]), ali taman dovoljno da razlika između dve učestalosti bude statistički značajna $\left(\chi^{2}(1, N=1800)=5.63, p=.018\right)$. Rezultati hi-kvadrat testova za odgovarajuće parove eksperimentalnih situacija, različitih jedino s obzirom na okvir pokazuju da je, od ukupno 6 parova zadataka odlučivanja, efekat okvira registrovan u dva slučaja, i to na niskim nivoima verovatnoće (5\% i 25\%). U preostala četiri slučaja, efekat okvira nije zabeležen.

Tabela 2

Rezultati logističke regresione analize (ZV: sklonost riziku)

\begin{tabular}{lccccc}
\hline Prediktor & $B$ & $S E_{\mathrm{B}}$ & $\exp (B)$ & Wald & $p$ \\
\hline Nivo verovatnće & 1.34 & 1.00 & 3.83 & 1.82 & .177 \\
Okvir & 1.16 & 0.34 & 3.20 & 11.50 & .001 \\
Okvir x Verovatnoća & -1.59 & 0.63 & 0.20 & 6.45 & .011 \\
Intercept & -2.04 & 0.56 & 0.13 & 13.49 & .000 \\
\hline
\end{tabular}

Napomena. $B$ = količnik šansi; $S E_{\mathrm{B}}=$ standardna greška količnika šansi; $\exp (B)=$ eksponenti količnika šansi; Wald = Waldov statistik; $p=$ nivo značajnosti. Za sve testove značajnosti $d f=1$. 


\section{Faktori efekta okvira}

U objavljenim metastudijama koje se bave efektom okvira, vidljivo je da se u istraživanjima efekta okvira rizičnog izbora, kao zavisna varijabla koristi sklonost ka izboru rizične opcije, tj. da se beleži procenat rizičnih izbora (Gambara \& Piñon, 2005; Kühberger, 1998; Levin, Schneider, \& Gaeth, 1998). Međutim, ukoliko želimo da ispitamo faktore efekta okvira, onda nam podaci o sklonosti ka riziku ne pružaju dovoljno informacija o samom efektu. Stoga smo u ovom istraživanju efekat okvira kao zavisnu varijablu operacionalizovali putem modelskog ponašanja (Tabela 3). Preciznije, svaki izbor sigurne opcije u pozitivnom okviru i svaki izbor rizične opcije u negativnom okviru posmatrali smo kao ponašanje koje je u skladu sa opisom fenomena, dok su suprotni izbori smatrani ponašanjem koje ukazuje na odsustvo efekta okvira. U istraživanjima dejstva okvira, ovakav pristup merenju efekta okvira predstavlja novinu.

Primenjeni kriterijum za operacionalizaciju efekta okvira je teorijski strog, pošto široka definicija efekta okvira obuhvata svaku promenu redosleda preferencija (jednosmerne, dvosmerne klasične i dvosmerne inverzne efekte), dok u ovom istraživanju korišćena varijabla modelsko ponašanje obuhvata efekte okvira definisane modelom teorije izgleda, odnosno klasičan dvosmerni efekat okvira.

Tabela 3

Modelsko ponašanje - kodiranje odgovora

\begin{tabular}{lcc}
\hline Izbor & Pozitivan okvir & Negativan okvir \\
\hline Sigurna opcija & 1 & 0 \\
Rizična opcija & 0 & 1 \\
\hline
\end{tabular}

Napomena. 0 = odsustvo modelskog ponašanja; 1 = prisustvo modelskog ponašanja.

Konkretno, svaka situacija u kojoj je ispitanik u pozitivnom okviru izabrao sigurnu opciju, kao i svaka situacija u kojoj je u negativnom okviru izabrana rizična opcija je kodirana brojem 1 (prisustvo modelskog ponašanja), a svaka situacija u kojoj je u pozitivnom okviru izabrana rizična i u negativnom okviru sigurna opcija je kodirana brojem 0 (odsustvo modelskog ponašanja). Takvim kodiranjem dobijeno je 600 pojedinačnih slučajeva, što nam je omogućilo da primenimo logističku regresionu analizu u kojoj smo kao kriterijum koristili kategoričku varijablu modelsko ponašanje.

Rezultati prikazani u Tabeli 3 pokazuju da je nivo verovatnoće statistički značajan prediktor efekta okvira kada je ERT smeštena u zonu gubitka. 
Tabela 4

Rezultati logističke regresione analze (ZV: modelsko ponašanje)

\begin{tabular}{lccccc}
\hline Prediktori & $B$ & $S E_{\mathrm{B}}$ & $\exp (B)$ & Wald & $p$ \\
\hline Nivo verovatnoće & -0.73 & 0.29 & 0.48 & 6.68 & .010 \\
Intercept & 0.54 & 0.16 & 1.72 & 10.92 & .001 \\
\hline
\end{tabular}

Napomena. $B=$ količnik šansi; $S E_{\mathrm{B}}=$ standardna greška količnika šansi; $\exp (B)=$ eksponenti količnika šansi; Wald = Waldov statistik; $p=$ nivo značajnosti. Za sve testove značajnosti $d f=1$.

Eksponent količnika šansi pokazuje da sa svakom promenom nivoa faktora verovatnoća, šansa da se registruje efekat okvira (modelsko ponašanje) opada 0.48 puta. Dakle, šanse da u pozitivnom okviru bude izabrana sigurna opcija, odnosno u negativnom rizična opcija, a u odnosu na šanse nemodelskog ponašanja, opadaju kada se prelazi sa jednog nivoa verovatnoće na drugi.

Kada se ovi podaci analiziraju uporedno sa podacima za isti domen odlučivanja prikupljenim u navedenom ranijem istraživanju (Damnjanović i Gvozdenović, 2014), zadataka ujednačenih po količini novca o kojoj se odlučuje, nivou verovatnoće i domenu odlučivanja, a razlikuju se samo s obzirom na eksperimentalnu referentnu tačku, rezultati binarne logističke regresije sa modelskim ponašanjem kao kriterijum pokazuju da postoji interakcija situacije u prologu zadatka i nivoa verovatnoće u predviđanju efekta okvira $\left(B=-0.59, \chi^{2}(1)=8.51, p=.004\right)$. Kada se promeni ERT, efekat okvira se registruje na nižim nivoima verovatnoće (Slika 3).

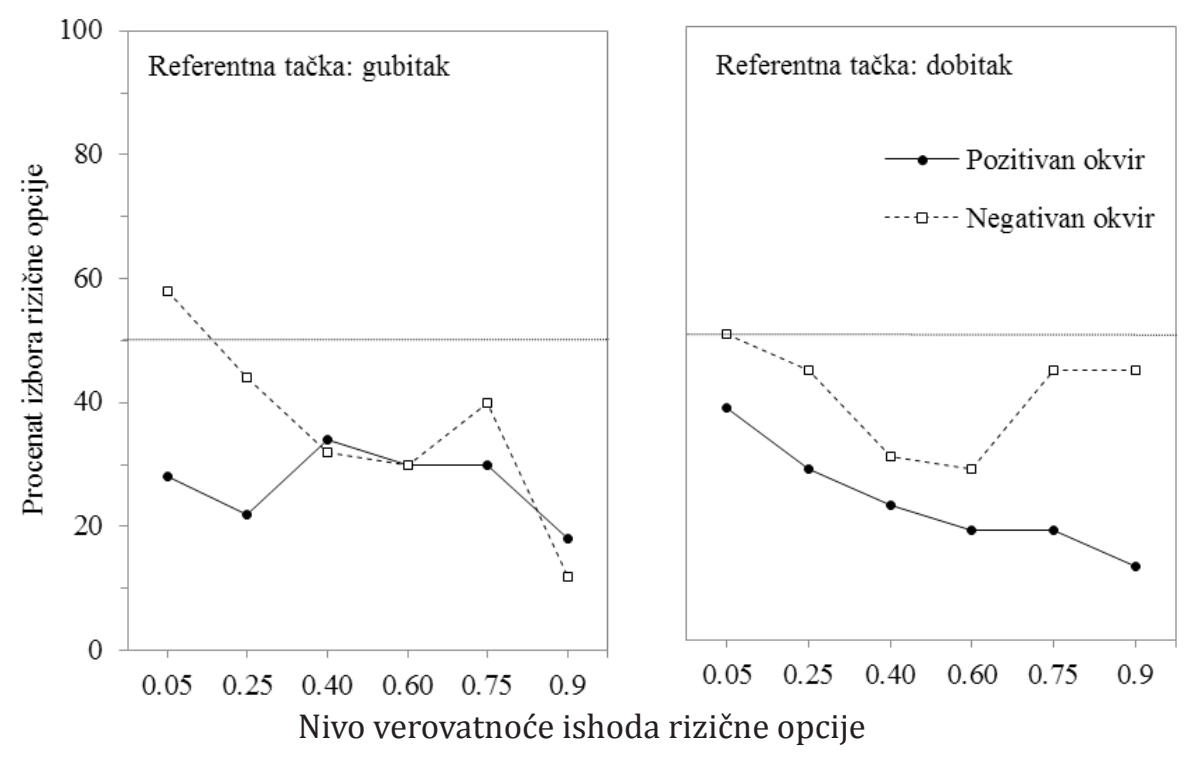

Slika 3. Procenat izbora rizične opcije kao funkcija nivoa verovatnoće ishoda rizične opcije u zadacima odlučivanja različitim s obzirom na ERT. 


\section{Diskusija}

Isti obrazac averzije prema riziku u domenu odlučivanja o novcu koji je registrovan i u ranijim istraživanjima, a odnosi se na smanjenu sklonost ka riziku u domenu odlučivanja o novcu (Fagley \& Miller, 1997; Kashima \& Maher, 1995; Schneider, 1992; Tversky \& Kahneman, 1981; Wang, 1996b), potvrđen je i nalazima našeg istraživanja. Sigurna opcija je značajno više birana u čak devet, od ukupno 12 zadataka. Međutim, u svim navedenim istraživanjima, ERT je u zoni dobitka, a merenje efekta okvira je vršeno poređenjem rizičnih izbora iz dva različita okvira. U našem istraživanju ERT je u zoni gubitika, čime smo nastojali da preciziramo odnos i doprinos različitih početnih pozicija sklonosti efektu okvira, a kao meru efekta okvira smo beležili izbore ispitanika u skladu sa teorijom izgleda.

U pozitivnom okviru sklonost ka riziku nije u odnosu sa nivoom verovatnoće, dok u negativnom okviru sa porastom nivoa verovatnoće povoljnog ishoda procenat izbora rizične opcije opada. Prediktorski status nivoa verovatnoće kada je eksperimentalna referentna tačka smeštena u zonu gubitka je suprotan u odnosu na situaciju kada je referentna tačka smeštena u zonu dobitka (Damnjanović i Gvozdenović, 2014), u kom verovatnoća jeste značajan prediktor rizičnog izbora u pozitivnom, ali nije u negativnom okviru. U aktuelnom eksperimentu, ispitanici su prinuđeni da biraju između sigurnog gubitka dela novca (plaćanja visokog računa) i rizičnog gubitka sa dva ishoda: gubitak celokupne sume novca i izbegavanje plaćanja računa (videti Prilog A). U negativnom okviru, sa porastom nivoa verovatnoće povoljnog ishoda rizične opcije sklonost ka rizičnom izboru opada, odnosno raste sklonost ka sigurnom izboru. Ovakav odnos ka riziku u negativnom okviru je suprotan predviđanjima teorije izgleda, pošto funkcija ponderisanja verovatnoća predviđa sklonost ka riziku na srednjim i velikim verovatnoćama gubitaka. Međutim, u zadacima odlučivanja sa porastom nivoa verovatnoće povoljnog ishoda rizične opcije, raste i neto-vrednost sigurne opcije, tačnije raste deo duga koji je kompanija spremna da oprosti, usled čega raste i poželjnost sigurne opcije. Drugim rečima, za ispitanika veću vrednost (korisnost) ima plaćanje malog procenta duga, nego makar i mali rizik da će morati da plati celu sumu koju duguje. Na primer, na najvišem nivou verovatnoće, rizični izbor bi podrazumevao zaista visoku verovatnoću od $90 \%$ da dug potpuno nestane i $10 \%$ da se plati čitav iznos, a sigurni da se ukupni dug smanji čak 10 puta (na 6000 dinara).

Osetljivost donosioca odluke na promenu prikazanog nivoa verovatnoće se očitava kroz dejstvo okvira, i to na specifičan način u situaciji gubitka. Okvir u ovako postavljenim situacijama rizičnog odlučivanja ostvaruje efekat, ali samo na dva najniža nivoa verovatnoće, i to dvosmerni efekat na nivou 5\% i jednosmerni na nivou $25 \%$. Drugim rečima, na ovim nivoima verovatnoće, pretpostavljamo da odnos između sigurne i rizične opcije nije u dovoljnoj meri jednoznačan za ispitanika, pa jezička manipulacija ima dejstvo. Ovo se posebno odnosi na najniži nivo, kada dogovor koji kompanija nudi o oprostu dela duga (sigurna opcija) iznosi samo 5\% (svega 3000 dinara) ukupnog duga, a verovatnoća da se ispitanik oslobodi duga promenom kompanije je takođe veoma niska. Igranje na sigurno u tom 
slučaju, ispitaniku spašava svega 3000 (od 60000) dinara. U situaciji gubitka, kada DO treba da plati račun, niži rizik za gubitak novca štiti odluku od dejstva okvira.

Nalazi ovog eksperimenta upućuju na zaključak da sklonost ka riziku i efekat okvira zavise od eksperimentalne referentne tačke. Teorijska razmatranja koja potiču iz normativnih modela odlučivanja upućuju na to da su DO generalno averzivni prema riziku. Međutim, dosadašnji nalazi (npr. Chang et al., 1987) ukazuju da ta averzija nije jednoznačna i da može zavisiti od toga da li donosilac odluke trošak (plaćanje računa u našem istraživanju, a poreza u navedenom istraživanju) opaža kao smanjenje prihoda ili kao gubitak, kao i od količine „spašenog” novca i strukture eventualnih posledica. Kada je prinudni izbor između sigurnog dobitka i rizičnog dobitka, okvir deluje na najvišim nivoima verovatnoće, i obrnuto, kada je izbor između sigurnog gubitka i rizičnog gubitka, okvir ostvaruje efekat na najnižim nivoima verovatnoće. Iako neki aspekti ovih nalaza, kao što su zabeležena sklonost ka riziku u negativnom okviru, različita ponašanja u zoni dobitka i u zoni gubitka (ali ne u smeru predviđenim modelom) jesu u skladu sa kumulativnom teorijom izgleda, različiti obrasci odlučivanja u zavisnosti od prologa zadatka nisu u potpunosti objašnjivi ovom teorijom. Uporedni nalazi nagoveštavaju različitu sklonost ka riziku i u zavisnosti od konteksta situacije u prologu, a ne samo u zavisnosti od okvira, subjektivne verovatnoće i referentne tačke. Doprinos sprovedenog istraživanja se ogleda i u metodološkom aspektu pristupa fenomenu efekta okvira, odnosno u preciznijoj operacionalizaciji fenomena i novom načinu merenja dejstva okvira na rizično odlučivanje.

Što se tiče ograničenja ovih nalaza, ona potiču kako iz prirode fenomena efekta okvira i teorijskog modela u okviru kog je ispitivan, tako i iz metodoloških aspekata našeg istraživanja. Za razliku od većine drugih kognitivnih pristrasnosti ili iluzija, efekat okvira nije moguće ispitati formom zadatka koja je u potpunosti apstraktna. Odnosno, i u slučajevima kada se osmisli apstraktni stimulus, takav nije nadređen konkretnijim stimulusima, već stoji u istoj ravni sa njima, tj. predstavlja prosto jedan od domena o kom se odlučuje. Domen u zadacima rizičnog odlučivanja ima ulogu nužnog moderatora (Damnjanović, 2013; Wang, 1996b) i zato ga treba posmatrati kao neodvojivo svojstvo strukture stimulusa, i u tom smislu, nalazi našeg istraživanja su nužno ograničeni na (zamišljeni) monetarni domen.

Premda psihološki pristup izučavanju odlučivanja, kao i ostali deskriptivni pristupi, temelje ima u teoriji izgleda, sama teorija Kahnemana i Tverskog se u literaturi svrstava u grupu formalnih, a ne u grupu kognitivnih modela (Kühberger, 2002). Iako model teorije izgleda nagoveštava i kognitivne elemente u odlučivanju, ni u originalnoj verziji teorije, ni u kumulativnoj teoriji izgleda, ti elementi nisu razrađeni, već samo implicirani kao različite psihofizičke funkcije koje stoje u osnovi odnosa prema gubicima i dobicima između kojih se nalazi referentna tačka (Kahneman \& Tversky, 1982; Tversky \& Kahneman, 1992). Pitanje kako kognitivni sistem operiše elementima zadatka rizičnog odlučivanja koje označavamo okvirom i verovatnoćom je svakako i dalje otvoreno. Cilj teorije izgleda bio je da se ponudi model koji će opisati kako se odlučivanje zaista odvija, i u tom smislu 
ima ograničene domete po tom pitanju, jer se takvim metodološkim pristupom ne ispituju direktno kognitivni mehanizmi koji su u osnovi odlučivanja.

Rezultati našeg istraživanja pokazuju da, i pored uloženog eksperimentatorovog napora da budu zavedeni kontekstom u kom je ishod prikazan, postoje nivoi verovatnoće u kojima ispitanici preslikavaju redosled preferencija iz pozitivnog u negativan okvir. Međutim, verovatnoća ishoda rizične opcije, kao jedan od činilaca očekivane vrednosti, je u sprovedenom istraživanja bila predstavljena faktorom koji je imao šest nivoa, a kontinuum je samo pretpostavljen, te bi u cilju preciznog opisa zavisnosti efekta okvira od prikazanog nivoa verovatnoće daljim ispitivanjima trebalo obuhvatiti čitav opseg verovatnoće (od 0 do 1 ). Dodatno, početna neto-vrednost o kojoj su naši ispitanici odlučivali (60000 RSD) je drugi činilac očekivane vrednosti i može se pretpostaviti da proširenje opsega vrednosti može da utiče na dejstvo okvira, te su naši nalazi ograničeni i u tom aspektu.

Rezultati ovog istraživanja su u skladu sa dosadašnjim nalazima koji upućuju na zaključak da averzija prema riziku nije jednoznačna i zavisi od toga da li DO trošak opaža kao smanjenje prihoda ili kao gubitak, kao i od količine „spašenog” novca. Zabeležena sklonost ka riziku u negativnom okviru i različita ponašanja u zonama dobitka i gubitka načelno jesu u skladu sa modelom odlučivanja teorije kumulativnih izgleda.

\section{Reference}

Allais, M. (1953). Le comportement de l'homme rationnel devant le risque: Critique des postulats et axiomes de l'école américaine. Econometrica: Journal of the Econometric Society, 503-546. doi:10.2307/1907921

Chang, O., Nichols, D., \& Schultz, J. (1987). Taxpayer attitudes toward tax audit risk. Journal of Economic Psychology, 8, 299-309. doi:10.1016/01674870(87)90025-0

Damnjanović, K. (2013). Efekat okvira: domen odlučivanja. Rad prezentovan na Naučno-stručnom skupu Savremeni trendovi u psihologiji, Novi Sad, Srbija.

Damnjanović, K. i Gvozdenović, V. (2014). Uticaj verovatnoće realizacije rizičnog ishoda na efekat okvira. Rad prezentovan na XX Naučnom skupu Empirijska istraživanja u psihologiji, Beograd, Srbija.

Fagley, N., \& Miller, M. (1997). Framing effects and arenas of choice. Organizational Behavior and Human Decision Processes, 71, 355-373. doi:10.1006/ obhd.1997.2725

Frisch, D. (1993). Reasons for framing effects. Organizational Behavior and Human Decision Processes, 54, 399-429. doi:10.1006/obhd.1993.1017

Gambara, H., \& Piñon, A. (2005). A meta-analytic review of framing effect: Risky, attribute and goal framing. Psicothema, 17, 325-331.

Ganzach, Y., \& Schul, Y. (1995). The influence of quantity of information and valence framing on decision. Acta Psychologica, 89, 23-36. doi:10.1016/00016918(94)00004-Z 
Haward, M., Murphy, R., \& Lorenz, J. (2008). Message framing and perinatal decisions. Pediatrics, 122, 109-118. doi:10.1542/peds.2007-0620

Huang. Y., \& Wang. L. (2010). Sex differences in framing effects across task domain. Personality and Individual Differences, 48, 649-665. doi:10.1016/j. paid.2010.01.005

Jou, J., Shanteau, J., \& Harris, R. (1996). An information processing view of framing effects: The role of causual-schemas in decision-making. Memory \& Cognition, 24, 1-15. doi:10.3758/BF03197268

Kahneman, D. (2011). Thinking, fast and slow. New York, USA: Farrar, Straus and Giroux.

Kahneman, D., \& Tversky, A. (1979). Prospect Theory: An analysis of decision under risk. Econometrica, 47, 263-291. doi:10.2307/1914185

Kashima, Y., \& Maher, P. (1995). Framing of decisions under ambiguity. Journal Behavioral Decision Making, 4, 249-262. doi:10.1002/bdm.3960080104

Kühberger, A. (1995). The framing of decisions: A new look at old problems. Organizational Behavior and Human Decision Processes, 62, 230-240. doi:10.1006/ obhd.1995.1046

Kühberger, A. (1998). The influence of framing on risky decisions: A Metaanalysis. Organizational Behavior and Human Decision Processes, 75, 23-55. doi:10.1006/obhd.1998.2781

Kühberger, A. (2002). Theoretical conceptions of framing effects in risky decisions. In R. Ranyard, W. Crozier, \& O. Svenson (Eds.), Decision making: Cognitive models and explanations (pp. 128-144). London, UK: Routledge.

Kühberger, A., \& Tanner, C. (2010). Risky choice framing: Task versions and a comparison of prospect theory and fuzzy-trace theory. Journal of Behavioral Decision Making, 23, 314-329. doi:10.1002/bdm.656

Levin, P., Schneider, S., \& Gaeth, G. (1998). All frames are not created equal: A typology and critical analysis of framing effects. Organizational Behavior and Human Decision Processes, 76, 149-188. doi:10.1006/obhd.1998.2804

Li, S., \& Adams, A. (1995). Is there something more important behind framing? Organizational Behavior and Human Decision Processes, 62, 216-219. doi:10.1006/obhd.1995.1044

Markowitz, H. (1952). The utility of wealth. The Journal of Political Economy, 60(2), 151-158.

Milićević, A., Pavličić, D. i Kostić, A. (2007). Odlučivanje u uslovima rizika i teorija izgleda. Psihologija, 40, 147-164.

Reyna, V., \& Brainerd, C. (1991). Fuzzy-trace theory and framing effects in choice: Gist extraction, truncation, and conversion. Journal Behavioral Decision Making, 4, 249-262. doi:10.1002/bdm.3960040403

Schneider, S. (1992). Framing and conflict: Aspiration level contingency, the status quo, and current theories of risky choice. Journal of Experimental Psychology: Learning, Memory, and Cognition, 18, 1040-1057. doi:10.1037/02787393.18.5.1040 
Shafir, E. (1993). Choosing versus rejecting: Why some options are both better and worse than others. Memory \& Cognition, 21, 546-556. doi:10.3758/ BF03197186

Sniezek, J., Paese, P., \& Switzer, F. (1990). The effect of choosing on confidence in choice. Organizational Behavior and Human Decision Processes, 46, 264-282. doi:10.1016/0749-5978(90)90032-5

Stajkić, B., \& Gvozdenović, V. (2014). Testing the house money effect in a game show: Mental accounting and asset integration. Primenjena psihologija, 7, 189-202.

Takemura, K. (1994). Influence of elaboration on the framing of decision. Journal of Psychology, 128, 33-39. doi:10.1080/00223980.1994.9712709

Thaler, R. H., \& Johnson, E. J. (1990). Gambling with the house money and trying to break even: The effects of prior outcomes on risky choice. Management science, 36(6), 643-660. doi: 10.1287/mnsc.36.6.643

Tversky, A., \& Kahneman, D. (1981). The framing of decisions and psychology of choice. Science, 211, 453-458. doi:10.1126/science.7455683

Tversky, A., \& Kahneman, D. (1992). Advances in prospect theory: Cumulative representation of uncertainty. Journal of Risk and Uncertainty, 5, 297-323. doi:10.1007/BF00122574

Urbany, E., \& Dickson, P. (1990). Prospect theory and pricing decisions. Journal of Behavioral Economics, 19, 69-80. doi:10.1016/0090-5720(90)90018-3

Wang, X. (1996a). Domain-specific rationality in human choices: Violations of utility axioms and social contexts. Cognition, 60, 31-63. doi:10.1016/00100277(95)00700-8

Wang, X. (1996b). Framing effects: Dynamics and task domains. Organizational Behavior and Human Decision Processes, 68, 145-157. doi:10.1006/ obhd.1996.0095

Wedell, D. (1997). Another look at reasons for choosing and rejecting. Memory \& Cognition, 25, 873-887. doi:10.3758/BF03211332

Wilson, E. B. (1927). Probable inference, the law of succession, and statistical inference. Journal of the American Statistical Association, 22(158), 209-212. doi:10.1080/01621459.1927.10502953 


\section{Prilog A}

Prikaz izrade stimulusa

Prikazani su stimulusi za prvi (najniži) nivo faktora verovatnoća - 5\% (verovatnoća povoljnog ishoda rizične opcije $\left(\mathrm{p}_{\mathrm{pov}}\right)$. Povećavanjem prikazanog nivoa verovatnoće, u obe opcije svakog od okvira menjala se i neto-vrednost sigurnog ishoda $\left(\mathrm{v}_{\text {sig }}\right)$ i verovatnoća nepovoljnog ishoda $\left(\mathrm{p}_{\text {nep }}\right)$ rizične opcije (da bi vrednost sigurne opcije bila ujednačena sa očekivanom vrednošću rizične opcije). Te vrednosti su prikazane masnim slovima. Svi ostali elementi zadataka na različitim nivoima verovatnoće su isti, pri čemu je u pitanju struktura klasičnog zadatka.

Monetarni domen - referentna tačka: gubitak

Prolog: Na vašem „pametnom telefonu“ se isključila opcija za kontrolu potrošenje prenosa podataka i stigao vam je račun u iznosu od 60000 dinara. Mobilni operater vam nudi mogućnost da uplatite određeni deo duga, a da ostatak ne morate da uplatite. Na raspolaganju imate dve mogućnosti:

Pozitivan okvir

Sigurna opcija: Ako odaberete plan A, kompanija će vam oprostiti deo ukupnog duga u iznosu od $\mathbf{3 0 0 0}$ dinara $\left(\mathrm{v}_{\text {sig }}\right)$.

Rizična opcija: Ako odaberete plan B i promenite kompaniju koja vam pruža telefosnke usluge, $\mathbf{5 \%}\left(\mathrm{p}_{\text {pov }}\right)$ je verovatnoća da se izvučete i potpuno izbegnete dug i $\mathbf{9 5 \%}\left(\mathrm{p}_{\text {nep }}\right)$ je verovatnoća da ne uspete da izbegnete naplatu.

Negativan okvir

Sigurna opcija: Ako odaberete plan A, moraćete da platite $\mathbf{5 7 0 0 0}$ dinara $\left(\mathrm{v}_{\mathrm{sig}}\right)$ kompaniji.

Rizična opcija: Ako odaberete plan B i promenite kompaniju koja vam pruža telefonske usluge, verovatnoća je $5 \%\left(\mathrm{p}_{\text {pov }}\right)$ da nećete platiti račun i $\mathbf{9 5 \%}$ $\left(\mathrm{p}_{\text {nep }}\right)$ da vam bude naplaćen ukupni iznos od 60000 dinara.

Koji plan ćete izabrati?

Tabela A1

Promene u zadacima na svim nivoima verovatnoće

\begin{tabular}{cccc}
\hline & \multicolumn{2}{c}{ Račun: 60000 RSD } \\
\hline $\mathrm{p}_{\mathrm{pov}}(\%)$ & $\mathrm{p}_{\text {nep }}(\%)$ & $\mathrm{v}_{\text {sig+ }}$ zadržano RSD & $\mathrm{v}_{\text {sig- }}$ naplaćeno RSD \\
\hline 5 & 95 & 3000 & 57000 \\
25 & 75 & 15000 & 45000 \\
40 & 60 & 24000 & 36000 \\
60 & 40 & 36000 & 24000 \\
75 & 25 & 45000 & 15000 \\
90 & 10 & 54000 & 6000 \\
\hline
\end{tabular}

Napomena. $\mathrm{p}_{\mathrm{pov}}+\mathrm{p}_{\mathrm{nep}}=100 \% ; \mathrm{v}_{\mathrm{sig}}=\mathrm{p}_{\mathrm{pov}} \mathrm{x}$ vrednost iz prologa. 


\section{Vasilije \\ Grozdenović}

Department of

Psychology, Faculty

of Philosophy,

University of Belgrade

\section{Kaja Damnjanović}

Laboratory for
Experimental
Psychology,
Department of
Psychology, Faculty
of Philosophy,
University of Belgrade

\section{INFLUENCE OF THE PROBABILTY LEVEL ON THE FRAMING EFFECT IN REFERENCE POINT OF LOSS}

Framing effect, which refers to preference reversal due to different descriptions of the same outcome, is examined through risky choice tasks, in which experimental reference point is typically positioned in win-area (situation of lottery). The aim of the conducted study was to examine a framing effect pattern as a function of the level of risk in risky options when experimental reference point is positioned in loss-area (paying a bill). Results show general loss aversion in monetary domain, which is in an accordance with previous studies. Frame influences decisions in the situations when possibility of total loss (level of risk) is perceived as relatively low. Interpretation of these results leads to the conclusion that the probability and reference point determine framing effect. In win-area, frame influences decisions on the highest levels of probability, and, vice-versa, in loss-area, frame influences decisions on the lowest levels of probability. Results confirm notion that risk-aversion is dependent upon a decision-maker's perception of spending (an investment or a loss). Although observed risk-seeking decisions in negative frame and different decision patterns in loss and win areas can be explained by the model of cumulative prospect-theory, influence of different experimental reference point can not.

Keywords: framing effect, risky choice, probability, reference point, loss 